\title{
A simple, affinity-based method for concentrating viruses from wastewater using engineered curli fibers
}

3 Daniel P. Birnbaum ${ }^{1,2}$, Katherine J. Vilardi ${ }^{3}$, Christopher L. Anderson ${ }^{3}$, Ameet J. Pinto ${ }^{4}$, Neel S.

4 Joshi $2 *$

$5 \quad{ }^{1}$ John A. Paulson School of Engineering and Applied Sciences, Harvard University, Cambridge, MA, United States.

$6 \quad{ }^{2}$ Department of Chemistry and Chemical Biology, Northeastern University, Boston, MA, United States.

$7 \quad{ }^{3}$ Department of Civil and Environmental Engineering, Northeastern University, Boston, MA, United States.

$8{ }^{4}$ School of Civil and Environmental Engineering, Georgia Institute of Technology, Atlanta, GA, United States.

$9 *$ Corresponding author: ne.joshi@northeastern.edu

11 Content summary: 9 pages, 6 figures, 3 tables

12

13

14 


\section{Supporting Information}

43

\section{Supplementary Figures}

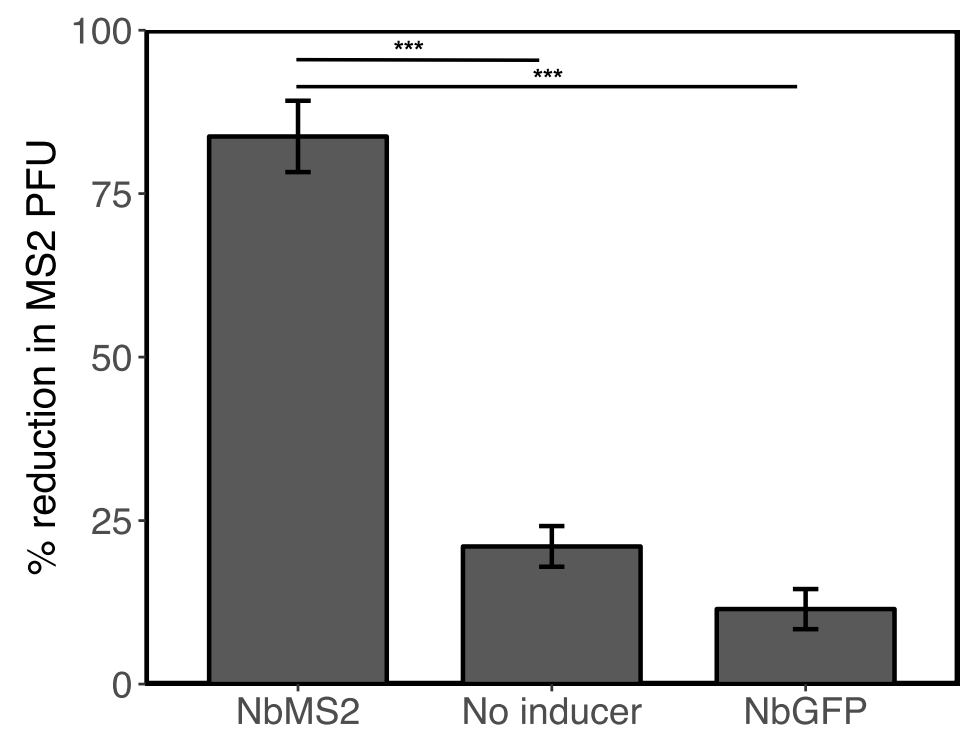

Figure S1. Spin-down of viable MS2 using engineered curli fibers. $1 \mathrm{~mL}$ of $E$. coli culture was transferred to a $2 \mathrm{~mL}$ Eppendorf tube. E. coli cells were spun down at $4000 \times \mathrm{g}$ for 5 minutes, re-suspended in $1 \mathrm{~mL}$ PBS, spun down again, and re-suspended in $0.5 \mathrm{~mL}$ PBS. $0.5 \mathrm{~mL}$ MS2 solution was added to reach a final concentration of $1.6 * 10^{6}$ plaque-forming units (PFU) per mL. MS2 solution was prepared by spiking from stock into PBS prior to assay. The mixture was incubated end-over-end at room temperature for 30 minutes. The mixture was spun down again, and the supernatant was sampled to measure the MS2 concentration using a plaque assay. When the curli fibers were engineered to display NbMS2, there was a significantly greater reduction in the concentration of viable MS2 remaining in the supernatant compared to controls where the cells were not induced to express curli fibers (twosided Student $t$-test for two means, P-value $=0.00057)$, or where the curli fibers were displaying an off-target nanobody (NbGFP) (two-sided Student $t$-test for two means, P-value $=0.00032)$. *** P-value $<0.001$. Values and error bars reflect the mean \pm standard error (s.e.) of three independent experiments $(n=3)$. 


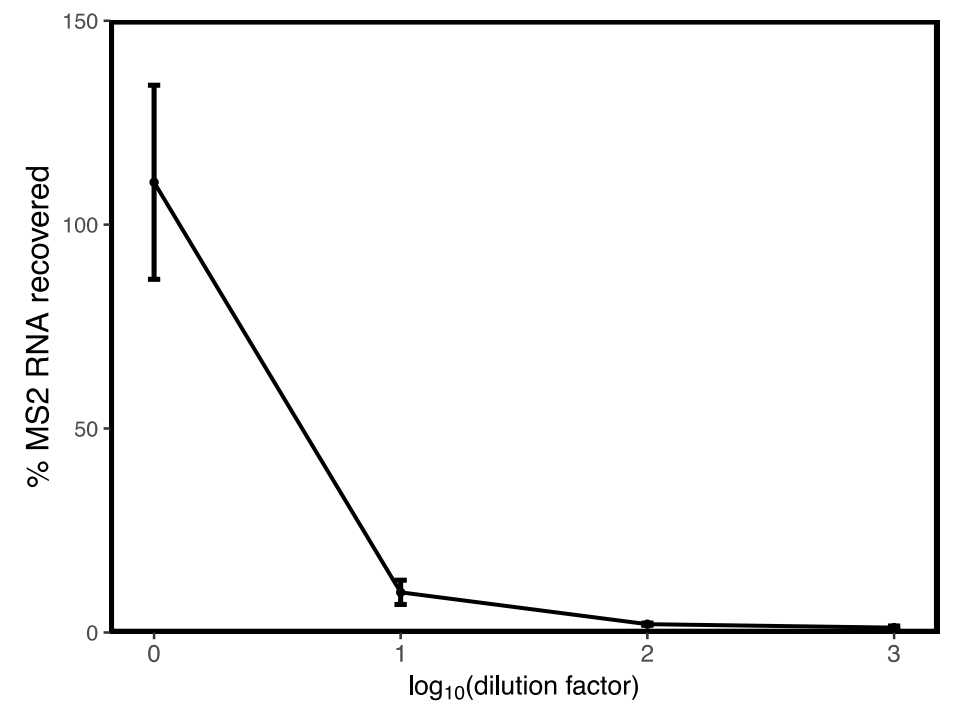

Figure S2. Recovery of MS2 from $20 \mathrm{~mL}$ of PBS was performed as described in the main text, with the $E$. coli cell density being varied and the concentration of MS2 kept constant at $1.6 * 10^{6} \mathrm{PFU} / \mathrm{mL}$. The $\mathrm{x}$-axis indicates the dilution factor of the $E$. coli suspension relative to the overnight culture cell density. For example, in the first data point, the $E$. coli cell density during the co-incubation with MS2 is equal to the overnight culture cell density, which varied between 2 and $2.5^{*} 10^{9} \mathrm{CFU} / \mathrm{mL}$. We found that a 10 -fold dilution of the $E$. coli cell suspension relative to the overnight culture cell density led to a concomitant 10-fold decrease in the recovery of MS2 RNA. Values and error bars reflect the mean \pm standard error (s.e.) of at least three independent experiments.

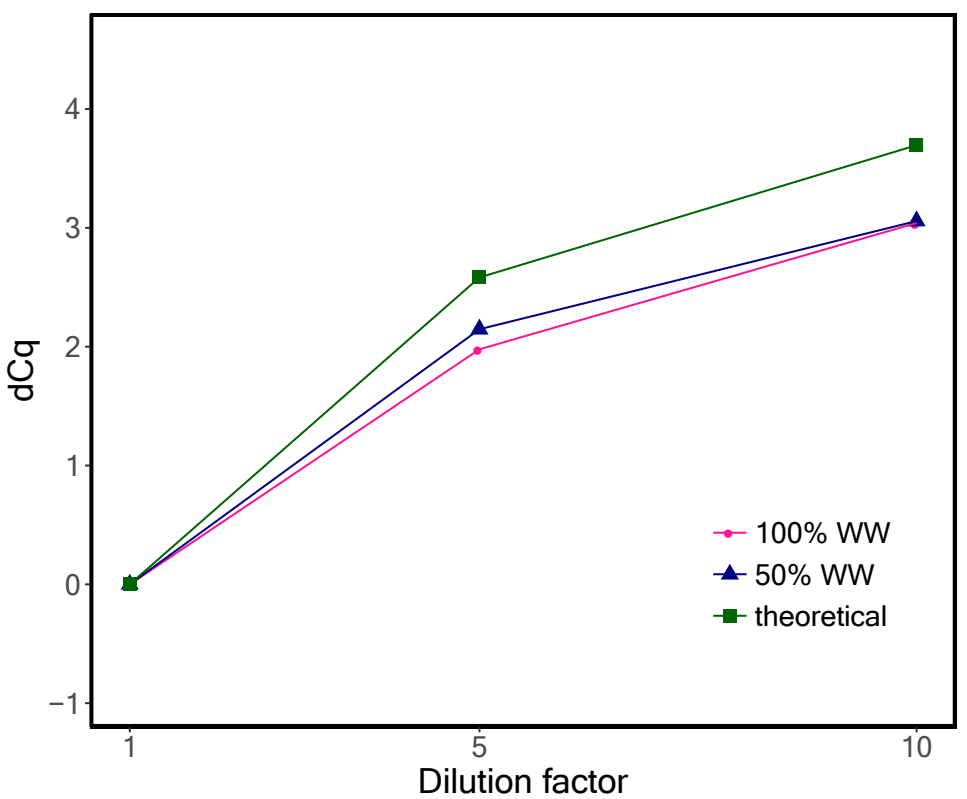

Figure S3. Testing for PCR inhibition. The spike-and-dilute method was used to assess PCR inhibition in RNA extract samples from curli fiber-based concentration of both $100 \%$ and $50 \%$ wastewater (WW). Synthetic MS2 RNA was spiked into RNA extract and diluted 1x, 5x, and 10x in nuclease-free water prior to qPCR analysis. The green line with square points represents the theoretically expected increase in $\mathrm{Cq}$ due to sample dilution, in the absence of PCR inhibition. The pink and blue lines with circular and triangular points indicate the actual increase in Cq with sample dilution for the $100 \% \mathrm{WW}$ and $50 \% \mathrm{WW}$ samples, respectively. The green band indicates $+/-1 \mathrm{Cq}$ around the expected $\mathrm{Cq}$ values to reflect assay variability. An increase in the measured $\mathrm{Cq}$ that is lower than the expected 
increase indicates inhibition. The RNA sample dilution factor is indicated on the $\mathrm{x}$-axis. The change in Cq value upon sample dilution is indicated on the y-axis.

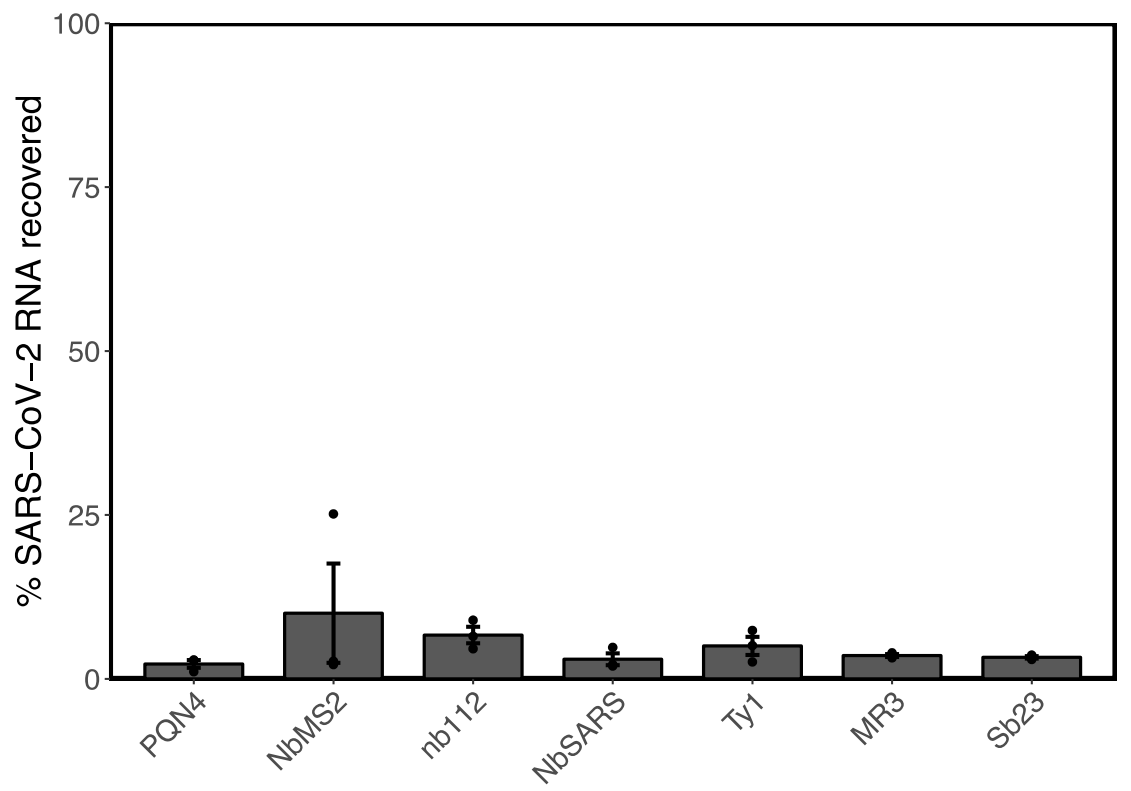

Figure S4. Attempted concentration of SARS-CoV-2 from wastewater. The concentration protocol was performed using $15 \mathrm{~mL}$ wastewater collected in March and April of 2021 in Somerville, MA. Several different curli fiber variants with demonstrated binding activity for the spike protein of SARS-CoV-2 were tested. For each sample, 15 $\mathrm{mL}$ wastewater was diluted 1:1 in curli fiber-containing PBS prior to spin-down. Percent recovery of SARS-CoV-2 RNA was calculated by comparison to a control in which RNA was directly extracted from $1 \mathrm{~mL}$ of pasteurized wastewater. PQN4 is a negative control where the cells do not contain a plasmid for inducible curli fiber expression. Values and error bars reflect the mean \pm s.e. of three independent experiments $(n=3)$.

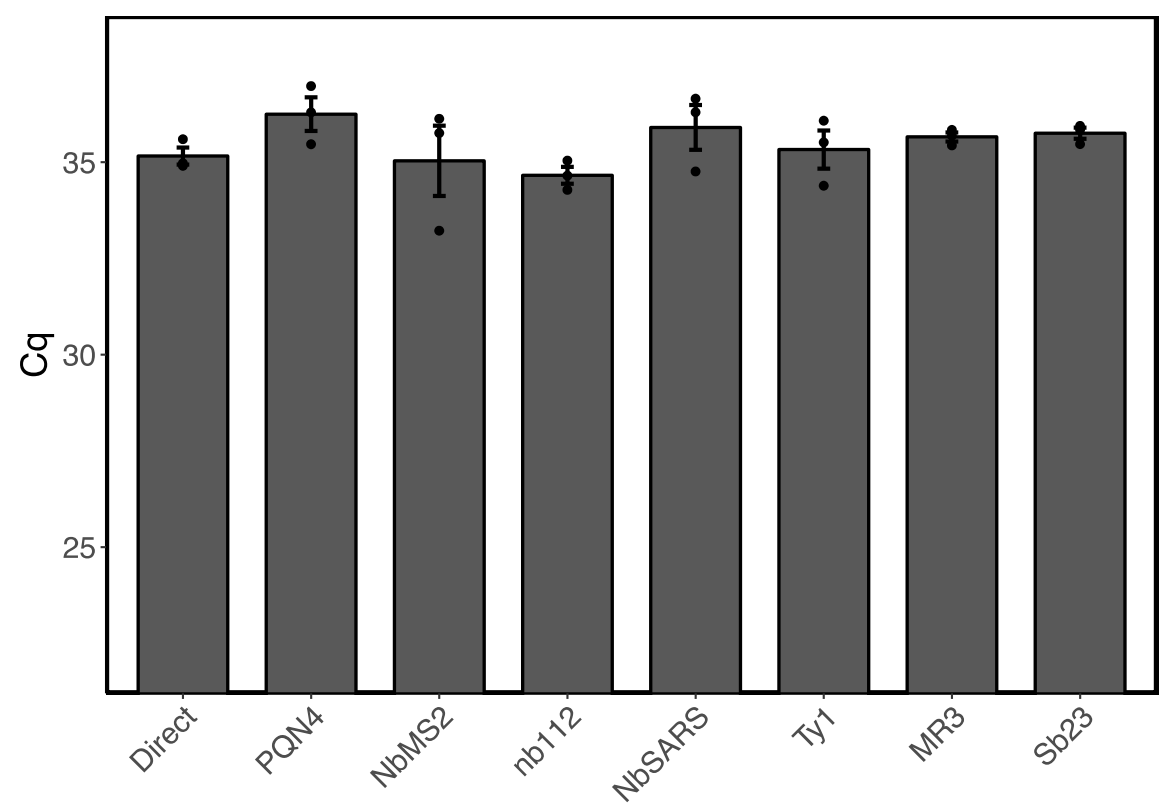


Figure S5. qPCR Cq values from attempted concentration of SARS-CoV-2 from wastewater. Values and error bars

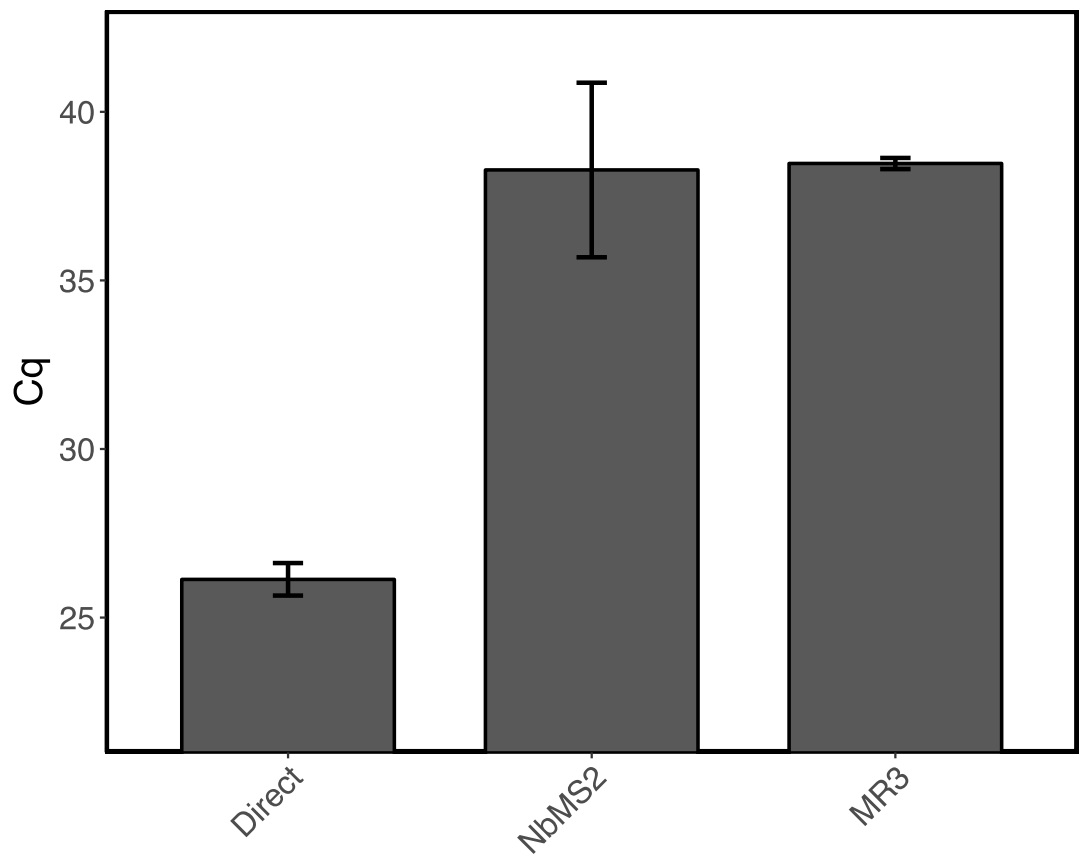

Figure S6. qPCR Cq values for detection of bCov process control. Values and error bars reflect the mean \pm s.e. of three independent experiments $(n=3)$.

\section{Supplementary Tables}

Table S1. Plasmids used in this study.

\begin{tabular}{|l|l|l|}
\hline Plasmid & Description & Source \\
\hline pBbB8k-csg-NbGFP & $\begin{array}{l}\text { Arabinose-inducible synthetic } \operatorname{csg} \text { operon in which } \\
\text { CsgA is fused to NbGFP, a nanobody domain specific } \\
\text { for GFP. }{ }^{[1]} \text { Derived from Addgene \#35363. }\end{array}$ & $\begin{array}{l}\text { Available at Addgene } \\
\text { \#166858. }\end{array}$ \\
\hline pBbB8k-csg-NbMS2 & $\begin{array}{l}\text { Arabinose-inducible synthetic } \operatorname{csg} \text { operon in which } \\
\text { CsgA is fused to NbMS2, a nanobody domain specific } \\
\text { for the coat protein of MS2. }{ }^{[2]}\end{array}$ & $\begin{array}{l}\text { This study. Available at } \\
\text { Addgene \#171701. }\end{array}$ \\
\hline pBbB8k-csg-nb112 & $\begin{array}{l}\text { Arabinose-inducible synthetic } \operatorname{csg} \text { operon in which } \\
\text { CsgA is fused to nb112, a nanobody domain specific } \\
\text { for the spike protein of SARS-CoV-2. }{ }^{[3]}\end{array}$ & $\begin{array}{l}\text { This study. Available at } \\
\text { Addgene \#171702. }\end{array}$ \\
\hline pBbB8k-csg-NbSARS & Same as above, with nanobody domain from [4]. & $\begin{array}{l}\text { This study. Available at } \\
\text { Addgene \#171703. }\end{array}$ \\
\hline pBbB8k-csg-D4 & Same as above, with nanobody domain from [5]. & This study. \\
\hline pBbB8k-csg-H4 & $\begin{array}{l}\text { Same as above, with a different nanobody domain from } \\
\text { [5]. }\end{array}$ & This study. \\
\hline pBbB8k-csg-Ty1 & Same as above, with nanobody domain from [6]. & This study. \\
\hline pBbB8k-csg-Sb23 & Same as above, with nanobody domain from [7]. & This study. \\
\hline pBbB8k-csg-MR3 & $\begin{array}{l}\text { Same as above, with nanobody domain from [Error! } \\
\text { Reference source not found.]. }\end{array}$ & This study. \\
\hline pBbB8k-csg-W25 & Same as above, with nanobody domain from [8]. & This study. \\
\hline
\end{tabular}




\begin{tabular}{|l|l|l|}
\hline pBbB8k-csg-Spikeplug & $\begin{array}{l}\text { Arabinose-inducible synthetic } \operatorname{csg} \text { operon in which } \\
\text { CsgA is fused to Spikeplug, a protein derived from the } \\
\text { ACE2 receptor. }{ }^{[10]}\end{array}$ & This study. \\
\hline pBbB8k-csg-22-57 & $\begin{array}{l}\text { Arabinose-inducible synthetic } \operatorname{csg} \text { operon in which } \\
\text { CsgA is fused to a peptide derived from the ACE2 } \\
\text { receptor. }{ }^{[1]}\end{array}$ & This study. \\
\hline
\end{tabular}

Table S2. RT-qPCR validation information

\begin{tabular}{|c|c|c|c|c|c|c|c|c|c|c|}
\hline Target & $\begin{array}{l}\text { Linear } \\
\text { dynamic } \\
\text { range } \\
\text { (orders of } \\
\text { magnitude) }\end{array}$ & $\begin{array}{l}\text { Lowest } \\
\text { quantity } \\
\text { on the } \\
\text { standard } \\
\text { curve } \\
\text { (Cq) }\end{array}$ & $\begin{array}{l}\text { Lowest } \\
\text { quantity on } \\
\text { the standard } \\
\text { curve (gene } \\
\text { copies per } \\
\text { reaction) }\end{array}$ & $\begin{array}{l}\text { Lowest } \\
\text { quantity on } \\
\text { the standard } \\
\text { curve }(\mathrm{Cq} \\
\text { standard } \\
\text { deviation) }\end{array}$ & slope & $\begin{array}{l}y- \\
\text { intercept }\end{array}$ & $\mathbf{R}^{2}$ & $\begin{array}{l}\text { PCR } \\
\text { efficiency }\end{array}$ & $\begin{array}{l}\text { Minimum } \\
\text { Cq of NTC } \\
\text { triplicates }\end{array}$ & $\begin{array}{l}\text { Intraassay } \\
\text { variation } \\
\text { (arithmetic } \\
\text { mean of } \\
\text { coefficient } \\
\text { of variation } \\
\text { of quantities } \\
\text { on each } \\
\text { plate) }\end{array}$ \\
\hline Rep & 4 & 34.864 & 168 & 0.425 & -3.249 & 42.32 & 0.9988 & 1.03 & negative & 23.829 \\
\hline Rep & 4 & 34.555 & 168 & 0.881 & -3.445 & 42.105 & 0.9997 & 0.95 & negative & 19.112 \\
\hline Rep & 4 & 35.655 & 168 & 0.289 & -3.383 & 43.217 & 0.9999 & 0.98 & negative & 27.662 \\
\hline N1 & 3 & 36.180 & 41 & 0.189 & -3.261 & 38.423 & 0.9888 & 1.03 & negative & 26.750 \\
\hline N1 & 3 & 35.889 & 41 & 0.039 & -3.308 & 38.269 & 0.9951 & 1.01 & negative & 41.209 \\
\hline
\end{tabular}

Table S3. MIQE guideline essential information checklist

\begin{tabular}{|c|c|}
\hline Requirement for submission & Response \\
\hline \multicolumn{2}{|c|}{ Experimental Design } \\
\hline Definition of experimental and control groups & $\begin{array}{l}\text { Experimental groups were defined as sterile buffer or } \\
\text { raw wastewater samples subjected to a given pre- } \\
\text { treatment, concentration and extraction protocol. }\end{array}$ \\
\hline Number within each group & $\begin{array}{l}\text { Three independent experiments were performed for each } \\
\text { experimental group, reflecting different biological } \\
\text { replicates for curli fiber expression, technical replicates } \\
\text { for concentration and RNA extraction procedures, and- } \\
\text { where relevant-different wastewater samples collected } \\
\text { on different weeks. }\end{array}$ \\
\hline \multicolumn{2}{|c|}{ Sample } \\
\hline Description & $\begin{array}{l}\text { PBS or wastewater obtained from a manhole in } \\
\text { Somerville, MA subjected to curli fiber-based } \\
\text { concentration and RNA extraction. }\end{array}$ \\
\hline Microdissection or macrodissection & $\mathrm{N} / \mathrm{A}$ \\
\hline Processing procedure & $\begin{array}{l}\text { Curli fiber-based concentration followed by Trizol- } \\
\text { based RNA extraction and purification using silica } \\
\text { column-based kit. For MS2 experiments, wastewater } \\
\text { was pre-pasteurized. }\end{array}$ \\
\hline If frozen, how quickly & N/A \\
\hline If fixed, with what and how quickly & $\mathrm{N} / \mathrm{A}$ \\
\hline Sample storage conditions and duration & $\begin{array}{l}\text { Wastewater samples were stored at } 4^{\circ} \mathrm{C} 1-2 \text { days. } \\
\text { Purified RNA samples were stored at }-80^{\circ} \mathrm{C} \text { for }<2 \\
\text { weeks. }\end{array}$ \\
\hline \multicolumn{2}{|c|}{ Nucleic Acid Extraction } \\
\hline Procedure and/or instrumentation & $\begin{array}{l}\text { RNA extraction was performed using Trizol reagent } \\
\text { (following manufacturer instructions). RNA purification }\end{array}$ \\
\hline
\end{tabular}




\begin{tabular}{|c|c|}
\hline & $\begin{array}{l}\text { was performed using PureLink RNA Mini Kit } \\
\text { (following instructions for Trizol-treated samples). }\end{array}$ \\
\hline Name of kit and details of any modifications & PureLink RNA Mini Kit (Life Technologies) \\
\hline Details of DNase or RNase treatment & $\mathrm{N} / \mathrm{A}$ \\
\hline Contamination assessment (DNA or RNA) & N/A \\
\hline Nucleic acid quantification & Absorbance at $260 \mathrm{~nm}$ \\
\hline Instrument and method & SpectraMax M5 Microplate Reader \\
\hline RNA integrity: method/instrument & $\mathrm{N} / \mathrm{A}$ \\
\hline RIN/RQI or $\mathrm{C}_{\mathrm{q}}$ of $3^{\prime}$ and $5^{\prime}$ transcripts & $\mathrm{N} / \mathrm{A}$ \\
\hline Inhibition testing & Spike-and-dilute method (see Figure S2) \\
\hline \multicolumn{2}{|c|}{ Reverse Transcription } \\
\hline Complete reaction conditions & $\begin{array}{l}\text { See "qPCR to quantify MS2 RNA" and "qPCR to } \\
\text { quantify SARS-CoV-2 RNA" sections. }\end{array}$ \\
\hline Amount of RNA and reaction volume & $\begin{array}{l}2 \text { or } 7 \mu \mathrm{L} \text { of RNA sample, in reaction volume of } 22 \text { or } \\
20 \mu \mathrm{L} \text {. }\end{array}$ \\
\hline Priming oligonucleotide and concentration & $\begin{array}{l}400 \text { or } 500 \mathrm{nM} \text {. See "qPCR to quantify MS2 RNA" and } \\
\text { "qPCR to quantify SARS-CoV-2 RNA" sections. }\end{array}$ \\
\hline Reverse transcriptase concentration & $\begin{array}{l}\text { Included in TaqMan Fast Virus 1-Step Master Mix } \\
\text { (ThermoFisher Scientific) and Luna WarmStart }{ }^{\circledR} \text { RT } \\
\text { Enzyme Mix (New England BioLabs). }\end{array}$ \\
\hline Temperature and time & $\begin{array}{l}\text { See "qPCR to quantify MS2 RNA" and "qPCR to } \\
\text { quantify SARS-CoV-2 RNA" sections. }\end{array}$ \\
\hline \multicolumn{2}{|c|}{ qPCR Target Information } \\
\hline Gene symbol & $\begin{array}{l}\text { Rep - MS2 RNA replicase } \beta \text { chain, N1 - SARS-CoV-2 } \\
\text { nucelocapsid }\end{array}$ \\
\hline Sequence accession number & Rep - NC 001417, N1 - MN908947.3 \\
\hline Amplicon length & Rep -68 bp, N1 -72 bp \\
\hline In silico specificity screen & $\mathrm{N} / \mathrm{A}$ \\
\hline Location of each primer by exon or intron & N/A \\
\hline What splice variants are targeted & $\mathrm{N} / \mathrm{A}$ \\
\hline \multicolumn{2}{|c|}{ qPCR Oligonucleotides } \\
\hline Primer sequences & $\begin{array}{l}\text { See "qPCR to quantify MS2 RNA" and "qPCR to } \\
\text { quantify SARS-CoV-2 RNA" sections. }\end{array}$ \\
\hline Location and identity of any modifications & $\mathrm{N} / \mathrm{A}$ \\
\hline \multicolumn{2}{|c|}{ qPCR Protocol } \\
\hline Complete reaction conditions & $\begin{array}{l}\text { See "qPCR to quantify MS2 RNA" and "qPCR to } \\
\text { quantify SARS-CoV-2 RNA" sections. }\end{array}$ \\
\hline Reaction volume and amount of cDNA & 20 or $22 \mu \mathrm{L}$, not applicable (1-Step RT-qPCR) \\
\hline Primer, probe, $\mathrm{Mg}^{2+}$, and dNTP concentrations & $\begin{array}{l}\text { Included in TaqMan Fast Virus 1-Step Master Mix } \\
\text { (ThermoFisher Scientific) and Luna Universal Probe } \\
\text { One-Step Reaction Mix (New England BioLabs). }\end{array}$ \\
\hline Polymerase identity and concentration & $\begin{array}{l}\text { Included in TaqMan Fast Virus 1-Step Master Mix } \\
\text { (ThermoFisher Scientific) and Luna Universal Probe } \\
\text { One-Step Reaction Mix (New England BioLabs). }\end{array}$ \\
\hline Buffer/kit identity and manufacturer & $\begin{array}{l}\text { TaqMan Fast Virus 1-Step Master Mix (ThermoFisher } \\
\text { Scientific) and Luna Universal Probe One-Step Reaction } \\
\text { Mix (New England BioLabs). }\end{array}$ \\
\hline Additives (SYBR Green I, DMSO, etc) & $\mathrm{N} / \mathrm{A}$ \\
\hline Complete thermocycling parameters & $\begin{array}{l}\text { See "qPCR to quantify MS2 RNA" and "qPCR to } \\
\text { quantify SARS-CoV-2 RNA" sections. }\end{array}$ \\
\hline Manufacturer of qPCR instrument & $\begin{array}{l}\text { QuantStudio } 3 \text { Real-Time PCR System (Applied } \\
\text { Biosystems) }\end{array}$ \\
\hline \multicolumn{2}{|c|}{ qPCR Validation } \\
\hline
\end{tabular}




\begin{tabular}{|l|l|}
\hline Specificity & $\begin{array}{l}\text { No detected amplification of "no template" controls in } \\
\text { any assay plate }\end{array}$ \\
\hline For SYBR Green I, $\mathrm{C}_{\mathrm{q}}$ of the NTC & N/A \\
\hline Calibration curves with slope and $y$ intercept & Table S2 \\
\hline PCR efficiency calculated from slope & Table S2 \\
\hline $\mathrm{R}^{2}$ of calibration curve & Table S2 \\
\hline Linear dynamic range & Table S2 \\
\hline $\mathrm{C}_{\mathrm{q}}$ variation at LoD & Table S2 \\
\hline Evidence for LoD & $\begin{array}{l}\text { For standard curves, wells corresponding to the } 6^{\text {th }} \text { point } \\
\text { in the dilution series consistently exhibited no detectable } \\
\text { amplification, showing evidence of LoD. }\end{array}$ \\
\hline If multiplex, efficiency and LoD of each assay & N/A \\
\hline \multicolumn{1}{|c|}{ Data } & Analysis \\
\hline qPCR analysis program & QuantStudio 3 Design and Analysis Software, v1.5.1 \\
\hline Method of $\mathrm{C}_{\mathrm{q}}$ determination & $\begin{array}{l}\text { Automatic thresholding via Design and Analysis } \\
\text { Software }\end{array}$ \\
\hline Outlier analysis & N/A \\
\hline Results for NTCs & Table S2 \\
\hline $\begin{array}{l}\text { Justification of number and choice of reference genes } \\
\text { for normalization method }\end{array}$ & N/A \\
\hline Number and stage of technical replicates & N/A \\
\hline Repeatability (intraassay variation) & Table S2 \\
\hline Statistical methods for results significance & See "Statistical Analysis" section \\
\hline Software (source, version) & RStudio, v1.0.44 \\
\hline
\end{tabular}

References

1. Rothbauer, Ulrich, Kourosh Zolghadr, Sergei Tillib, Danny Nowak, Lothar Schermelleh, Anja Gahl, Natalija Backmann, et al. 2006. "Targeting and Tracing Antigens in Live Cells with Fluorescent Nanobodies." Nature Methods 3 (11): 887-89. https://doi.org/10.1038/nmeth953.

2. Liu, Jinny L., Daniel Zabetakis, Ellen R. Goldman, and George P. Anderson. 2013. "Selection and Evaluation of Single Domain Antibodies toward MS2 Phage and Coat Protein." Molecular Immunology 53 (1-2): 118-25. https://doi.org/10.1016/j.molimm.2012.07.010.

3. Esparza, Thomas J., Negin P. Martin, George P. Anderson, Ellen R. Goldman, and David L. Brody. 2020. "High Affinity Nanobodies Block SARS-CoV-2 Spike Receptor Binding Domain Interaction with Human Angiotensin Converting Enzyme." Scientific Reports 10 (1): 22370. https://doi.org/10.1038/s41598-020-79036-0.

4. Wrapp, Daniel, Dorien De Vlieger, Kizzmekia S. Corbett, Gretel M. Torres, Nianshuang Wang, Wander Van Breedam, Kenny Roose, et al. 2020. "Structural Basis for Potent Neutralization of Betacoronaviruses by Single-Domain Camelid Antibodies.” Cell 181 (5): 1004-1015.e15. https://doi.org/10.1016/j.cell.2020.04.031.

5. Huo, Jiandong, Audrey Le Bas, Reinis R. Ruza, Helen M. E. Duyvesteyn, Halina Mikolajek, Tomas Malinauskas, Tiong Kit Tan, et al. 2020. "Neutralizing Nanobodies Bind SARS-CoV-2 Spike RBD and Block Interaction with ACE2." Nature Structural \& Molecular Biology 27 (9): 846-54. https://doi.org/10.1038/s41594-020-0469-6.

6. Hanke, Leo, Laura Vidakovics Perez, Daniel J. Sheward, Hrishikesh Das, Tim Schulte, Ainhoa Moliner-Morro, Martin Corcoran, et al. 2020. "An Alpaca Nanobody Neutralizes SARS-CoV-2 by Blocking Receptor Interaction.” Nature Communications 11 (1): 4420. https://doi.org/10.1038/s41467-020-18174-5.

7. Custódio, Tânia F., Hrishikesh Das, Daniel J. Sheward, Leo Hanke, Samuel Pazicky, Joanna Pieprzyk, Michèle Sorgenfrei, et al. 2020. "Selection, Biophysical and Structural Analysis of 
Synthetic Nanobodies That Effectively Neutralize SARS-CoV-2." Nature Communications 11 (1): 5588. https://doi.org/10.1038/s41467-020-19204-y.

8. Li, Tingting, Hongmin Cai, Hebang Yao, Bingjie Zhou, Ning Zhang, Martje Fentener van Vlissingen, Thijs Kuiken, et al. 2021. "A Synthetic Nanobody Targeting RBD Protects Hamsters from SARS-CoV-2 Infection." Nature Communications 12 (1): 4635.

9. Valenzuela Nieto, Guillermo, Ronald Jara, Daniel Watterson, Naphak Modhiran, Alberto A. Amarilla, Johanna Himelreichs, Alexander A. Khromykh, et al. 2021. "Potent Neutralization of Clinical Isolates of SARS-CoV-2 D614 and G614 Variants by a Monomeric, Sub-Nanomolar Affinity Nanobody." Scientific Reports 11 (1): 3318. https://doi.org/10.1038/s41598-021-82833W.

10. Romano, Maria, Alessia Ruggiero, Flavia Squeglia, and Rita Berisio. 2020. "An Engineered Stable Mini-Protein to Plug SARS-Cov-2 Spikes." Preprint. bioRxiv. https://doi.org/10.1101/2020.04.29.067728.

11. Yang, Jinsung, Simon J. L. Petitjean, Melanie Koehler, Qingrong Zhang, Andra C. Dumitru, Wenzhang Chen, Sylvie Derclaye, Stéphane P. Vincent, Patrice Soumillion, and David Alsteens. 2020. "Molecular Interaction and Inhibition of SARS-CoV-2 Binding to the ACE2 Receptor." Nature Communications 11 (1): 4541. https://doi.org/10.1038/s41467-020-18319-6. 